Tropical Journal of Pharmaceutical Research December 2017; 18 (4): 773-780

ISSN: 1596-5996 (print); 1596-9827 (electronic) (1) Pharmacotherapy Group, Faculty of Pharmacy, University of Benin, Benin City, 300001 Nigeria.

\title{
Development of reduced-salt gel of silver carp meat batter using low frequency ultrasound: Effect on color, texture, cooking loss and microstructure
}

\author{
Riya Liuhartana Nasyiruddin ${ }^{1,2}$, Willard Burton Navicha ${ }^{1,3}$, Abuubakar Hassan \\ Ramadhan', Fang Yang ${ }^{1}$, Qixing Jiang ${ }^{1}$, Yanshun $\mathrm{Xu}^{1}$, Peipei $\mathrm{Yu}^{1}$, Wenshui \\ $\mathrm{Xia}^{1 *}$ \\ ${ }^{1}$ State Key Laboratory of Food Science and Technology, School of Food Science and Technology, Collaborative Innovation \\ Center of Food Safety and Quality Control in Jiangsu Province, Jiangnan University, Wuxi, Jiangsu 214122, China, ${ }^{2}$ The \\ Fishery Faculty, University of PGRI Palembang, Palembang, South Sumatera, 30263, Indonesia, ${ }^{3}$ Department of Human \\ Ecology, Domasi College of Education, PO Box 49, Domasi, Zomba, Malawi
}

*For correspondence: Email: xiaws@jiangnan.edu.cn; Tel: +8651085919121

\begin{abstract}
Purpose: To develop reduced-salt silver carp meat gels using low frequency ultrasound.

Methods: Silver carp meat batters were prepared with 0.5, 1 (reduced-salt) and $2 \%$ (regular salt), and sonicated $(20 \mathrm{KHz}, 500 \mathrm{~W})$ for 30 and $40 \mathrm{~min}$, or unsonicated (control). Changes in gel properties were evaluated in terms of color, texture, cooking loss and microstructure using color measurement, puncture test, cooking loss and scanning electron microscopic (SEM) analysis, respectively.

Results: Ultrasound and salt exposure led to marked effects on color, texture and cooking loss in fish meat gels $(p<0.05)$. Reduction in salt content increased the lightness $\left(L^{*}\right)$ and cooking loss; and also decreased the sample values of greenness $\left(-a^{*}\right)$, breaking force, rupture distance and gel strength. Scanning electron microscopy (SEM) on regular-salt level samples showed that ultrasonic exposure decreased dense aggregates and increased the number and distribution of small cavity samples. Reduced-salt samples (1\% salt) subjected to 30 min sonication had better color (lighter) than control $(0$ min sonication), better texture (higher gel strength) and cooking loss comparable to that of regular-salt level sample subjected to 30 min sonication, and similar to microstructures from normal salt samples without ultrasound exposure.

Conclusion: Low frequency ultrasound is suitable for preparing reduced-salt fish meat gels under suitable ultrasonic conditions.
\end{abstract}

Keywords: Silver carp, Fish meat batter, Gel, Reduced salt, Low frequency ultrasound

This is an Open Access article that uses a fund-ing model which does not charge readers or their institutions for access and distributed under the terms of the Creative Commons Attribution License (http://creativecommons.org/licenses/by/4.0) and the Budapest Open Access Initiative (http://www.budapestopenaccessinitiative.org/read), which permit unrestricted use, distribution, and reproduction in any medium, provided the original work is properly credited.

Tropical Journal of Pharmaceutical Research is indexed by Science Citation Index (SciSearch), Scopus, International Pharmaceutical Abstract, Chemical Abstracts, Embase, Index Copernicus, EBSCO, African Index Medicus, JournalSeek, Journal Citation Reports/Science Edition, Directory of Open Access Journals (DOAJ), African Journal Online, Bioline International, Open-J-Gate and Pharmacy Abstracts

\section{INTRODUCTION}

Silver carp (Hypophthalmichthys molitrix) is one of the major inexpensive freshwater fish species harvested commercially in China [1]. In recent years, food products such as fermented sausages [2], surimi [3-5] and restructured fish [1] have been developed from silver carp. 
Common salt or sodium chloride is a vital additive in the processing of many foods. However, excessive sodium intake is associated with hypertension [6]. Aligned with that, there is a great interest in reduced-salt products. However, reduction in salt content could influence the characteristics of meat products. Reduced salt content impairs the complete solubilization or dissociation of myofibrillar proteins, thereby contributing to coarse product structure [4]. Moreover, it has been shown that salt concentrations below $2 \%$ negatively affect the mechanical and functional attributes of fish products [7].

Ultrasound is a novel, harmless and ecocompatible technique employed in food industries for production of food products. It involves the use of mechanical waves with frequencies beyond the auditory threshold of humans. In the food processing industries, ultrasound waves of low frequency are employed for altering the physical and chemical properties of foods [8], while those of high frequencies are useful for assessing the physicochemical attributes foods. Some studies have reported the enhancing effect of low frequency ultrasound on the properties of meat protein [8-11]. According to $\mathrm{Li}$ et al [12], ultrasound waves are capable of improving the properties of low-salt gels. In addition, it has been suggested that ultrasound parameters such as the type of equipment, frequency, and time and power of sonication should be considered in research studies $[8,13]$.

The aim of the present study was to develop reduced-salt gels of silver carp meat batters using low frequency ultrasound. Available literature shows that there is limited information on this area of research.

\section{EXPERIMENTAL}

\section{Materials}

Fresh live silver carp fish (mean weight $=2.5 \pm$ $0.2 \mathrm{~kg}$ ) were purchased from a local supermarket (Wuxi, Jiangsu, China). Trained store personnel sacrificed the fish using percussive stunning. Then the fish were scaled, eviscerated, decapitated and washed in running tap water. Thereafter, they were covered with crushed ice, and transported to Food Processing Technology Laboratory within $20 \mathrm{~min}$. Then, the fish were manually skinned and filleted. Only the white muscles were used: the red muscles were manually removed with a knife. The muscles were passed through a grinder using a 7-mm plate (MGJ-090, Foshan Shunde Mingjian, Guangdong, China). Samples were placed in polyethylene bags and kept at $4{ }^{\circ} \mathrm{C}$ prior to preparation of meat batter. All of the chemicals and reagents used in this study were of analytical grade (Sinopharm Chemical Reagent, Shanghai, China).

\section{Meat batter preparation}

The meat batter samples were prepared with three levels of salt $(\mathrm{NaCl})$ namely $0.5,1 \%$ (reduced-salt concentrations) and $2 \%$ (regularsalt concentration); and three levels of ultrasound treatment, namely $0 \mathrm{~min}$ (unsonicated sample used as control), $30 \mathrm{~min}$ and $40 \mathrm{~min}$. The meat batters were prepared in line with a modified version of the procedure described earlier [14]. The preparation procedure was as follows: ground meat was homogenized in a food processor (JYL-D025, Joyoung, Shandong, China) with ice-cold water for $30 \mathrm{~s}$, and salt was added at different concentrations as indicated in Table 1, followed with chopping for $30 \mathrm{sec}$. Approximately $60 \mathrm{~g}$ of each meat batter was placed in a plastic bag, spread out to a thickness of about $2 \mathrm{~mm}$, and vacuum-sealed.

Table 1: Composition of the fish meat batters

\begin{tabular}{|c|c|c|c|}
\hline \multirow[t]{2}{*}{ Ingredient } & \multicolumn{3}{|c|}{ Salt levels (\%) } \\
\hline & 0.5 & 1 & 2 \\
\hline Fish meat & 80.0 & 80.0 & 80.0 \\
\hline Salt & 0.5 & 1.0 & 2.0 \\
\hline Ice water & 19.5 & 19.0 & 18.0 \\
\hline Total & 100.0 & 100.0 & 100.0 \\
\hline
\end{tabular}

This was performed using a probe system (Intelligent Ultrasonicator Generator USC201L, $500 \mathrm{~W}$ and $20 \mathrm{kHz}$, Hangzhou Biao, Hangzhou, China) equipped with horn of $10 \mathrm{~mm}$ diameter.

The sample was immersed in $1500 \mathrm{~mL}$ iced-cold water in a $2000-\mathrm{mL}$ glass beaker. The beaker was placed in ice bath. During the ultrasound application, the temperature of the iced-cold water was maintained below $15^{\circ} \mathrm{C}$. The distance between sample and tip of the probe was established at $2 \mathrm{~cm}$. the meat batters were sonicated for periods of 30 and $40 \mathrm{~min}$. Measurements were taken in triplicate. Meat batter not subjected to sonication served as control at the same temperature $\left(15^{\circ} \mathrm{C}\right)$. Samples were stored at $4{ }^{\circ} \mathrm{C}$ prior to analysis.

Meat gel was prepared as follows: after the ultrasound treatment, meat batter portions (about $35 \mathrm{~g}$ ) were placed in plastic centrifuge tubes of inner diameter $2.5 \mathrm{~cm}$, and height $10 \mathrm{~cm}$. The tubes were hermetically sealed. The sealed 
tubes were centrifuged at $2500 \mathrm{~g}$ at $3{ }^{\circ} \mathrm{C}$ for 15 min using Sigma Laboratory Centrifuges $4 \mathrm{~K} 15$, Germany. Thereafter, the tubes were heated in a water bath at $40{ }^{\circ} \mathrm{C}$ for $1 \mathrm{~h}$, and at $90{ }^{\circ} \mathrm{C}$ for 15 $\mathrm{min}$. Then, the meat gels were immediately cooled by immersing the tubes in ice-cold water at $4{ }^{\circ} \mathrm{C}$ for $30 \mathrm{~min}$. The meat gels were stored in a refrigerator at $4{ }^{\circ} \mathrm{C}$ prior to further analysis.

\section{Color measurement}

The meat gels were sliced into cylinder-shaped patterns of diameter $2.5 \mathrm{~cm}$ and length $2.0 \mathrm{~cm}$. The color of the sample surfaces was determined with a color spectrophotometer (UltraScan, USA), after prior calibration using a white and black standard plate. Color was measured at four different points on a sample to get the magnitudes of lightness $\left(L^{*}\right)$, redness $\left(+a^{*}\right)$, greenness $\left(-a^{*}\right)$, yellowness $\left(+b^{*}\right)$ or blueness $(-$ $\left.b^{*}\right)$ of the gels. The measurements were carried out in triplicate.

\section{Puncture test}

Puncture test was performed in line with a modified version of the procedure reported earlier [12]. The test was done on cylindershaped slices of meat gels (same dimensions as in color measurement) with TA.XT Plus texture analyzer bearing a 5-mm diameter plunger operating at a velocity of $1 \mathrm{~mm} / \mathrm{sec}$. The parameters measured were distance to rupture (cm) and breaking force (g). Gel strength, expressed in the unit of $\mathrm{g} . \mathrm{cm}$, was obtained from the product of breaking force and distance to rupture. The test was repeated six times for each sample at room temperature.

\section{Cooking loss analysis}

This was determined using a modified version of the procedure outlined previously [15]. Portions of each meat batter (approximately $10 \mathrm{~g}$ ) were processed to meat gel using meat gel preparation as described above. The tubes were kept in inverted position for $1 \mathrm{~h}$, and filter paper (Whatman no. 1 with diameter $90 \mathrm{~mm}$ ) was put on the open tubes to absorb separated fluid. Cooking loss was estimated in terms of postcooking weight decrease (\%) relative to original weight. Measurements were done in triplicate.

\section{SEM of meat gels}

The ultra-structures of the 4 meat gel samples (sample containing $1 \%$ salt with $30 \mathrm{~min}$ ultrasound, and samples containing $2 \%$ salt subjected to 0, 30 and 40 min ultrasound) were examined under SEM (SU1510, Hitachi, Tokyo,
Japan) which was set at the operating voltage of $5 \mathrm{kV}$ and at a magnification of $\times 3 \mathrm{k}$. Prior to SEM, the 4 samples were processed with a modified version of an earlier method [12]. The samples were subjected to fixation for $48 \mathrm{~h}$ using phosphate buffered solution of $2.5 \%$ glutaraldehyde, $\mathrm{pH}$ 7.0. Following fixation, the samples were rinsed thrice with $0.1 \mathrm{M}$ phosphate buffer at the same $\mathrm{pH}$, and then dehydrated through increasing ethanol concentrations (30$100 \%)$. Finally, the dehydrated samples were dried in a freeze drier dryer (Alpha 1-2 LDplus, Germany).

\section{Statistical analysis}

Data were subjected to statistical analysis using ANOVA. Groups were compared with Duncan's multiple range tests. All analyses were carried out with SPSS 20.0 software. Statistical significance of difference was assumed at $p<$ 0.05 .

\section{RESULTS}

\section{Color}

The values of $L^{*}, a^{*}$ and $b^{*}$ for fish meat gels are shown in Figure 1. The $L^{*}$ value varied from 78.31 to $81.27 ; a^{*}$ value varied from -1.07 to 1.83 , while $b^{*}$ value varied from 7.20 to 9.74 .

There were marked increases in $L^{*}$ values of fish meat gels subjected to ultrasound for $30 \mathrm{~min}$ and 40 min, with decreasing $\mathrm{NaCl}$ content $(p<0.05)$. In addition, the $L^{*}$ values of regular-salt fish meat gels were reduced by ultrasound exposure. However, the $-a^{*}$ values at decreasing $\mathrm{NaCl}$ levels were reduced by ultrasound exposure for the two periods of time. Furthermore, at normal $\mathrm{NaCl}$ level, there were increases in $-a^{*}$ value as a result of ultrasound exposure.

With decreased $\mathrm{NaCl}$ content, the $b^{*}$ level was enhanced by the two ultrasound exposure periods, while in samples with normal $\mathrm{NaCl}$ content, $b^{*}$ was reduced as a function of duration of ultrasound exposure. However, in samples containing $1 \% \mathrm{NaCl}$, ultrasound exposure had no marked effect on $b^{*}$ value.

\section{Puncture test}

The breaking force values of fish meat gels varied from 186.55 to $291.66 \mathrm{~g}$. The distance to rupture values varied from 0.56 to $0.86 \mathrm{~cm}$, while the gel strength varied from 107.15 to 251.12 g.cm (Figure 2). The breaking force decreased in decreased $\mathrm{NaCl}$ content as a function of duration of ultrasound exposure, while it was enhanced as 

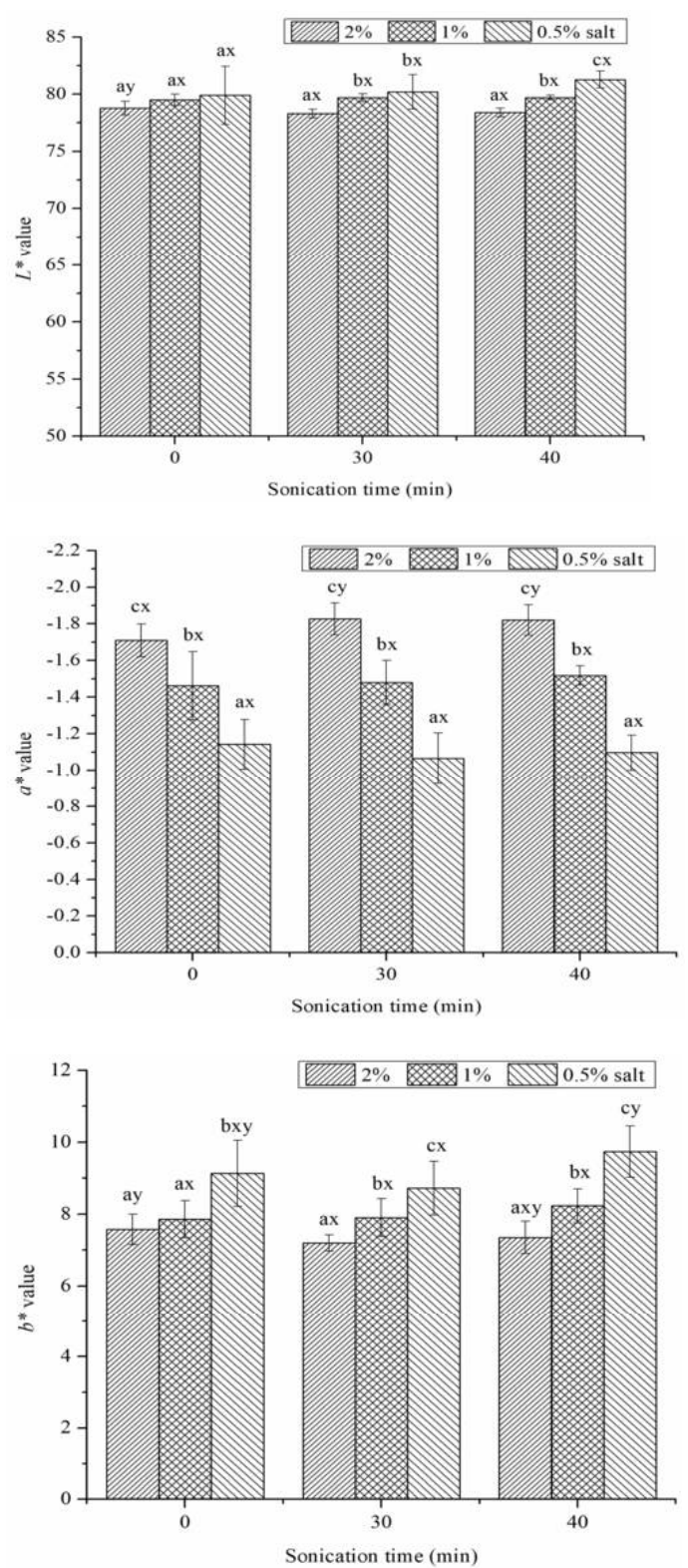

Figure 1: Color of fish meat gels. Different letters ( $a, b$ and $\mathrm{c}$ ) indicate significant differences $(p<0.05)$ among different salt levels at the same sonication time. The letters $x$ and $y$ indicate significant differences $(p<0.05)$ between the sonication times at the same salt level

a function of ultrasound exposure duration in samples with normal $\mathrm{NaCl}$ content.

The distance of rupture of samples decreased with reducing salt levels at the two ultrasound treatments. Moreover, the distance of rupture increased significantly with ultrasound treatments in samples with normal salt levels, such that a sample with $40 \mathrm{~min}$ ultrasound had higher distance of rupture than the control.

The gel strength value of samples decreased in sample with decreased $\mathrm{NaCl}$ content and with increase in ultrasound exposure time, but increased with ultrasound exposure period at normal $\mathrm{NaCl}$ content.
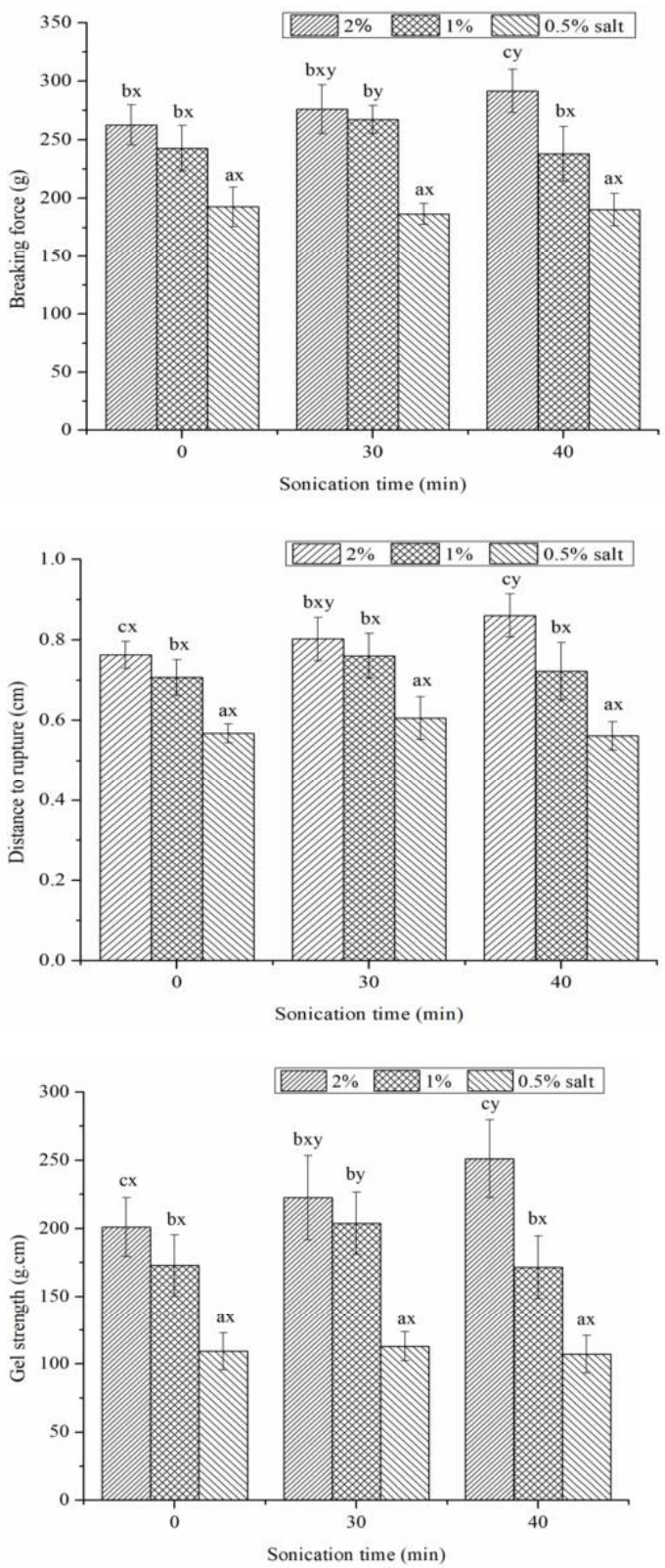

Figure 2: Distance to rupture, breaking force, and gel strength of the fish meat gels. Different letters $(a, b$ and c) reflect significant differences $(p<0.05)$ among samples with different salt contents at the same sonication time. The letters $\mathrm{x}$ and $\mathrm{y}$ indicate significant differences $(p<0.05)$ between the two sonication periods at the same salt level

\section{Cooking loss}

The results of cooking losses in fish meat gels are presented in Figure 3 . The values ranged from 10.76 to $16.16 \%$. Cooking loss was enhanced with reduction in $\mathrm{NaCl}$ content of fish meat gels as a function of duration of ultrasound exposure. In samples with normal $\mathrm{NaCl}$ contents, 
cooking loss was markedly enhanced by ultrasound exposure.

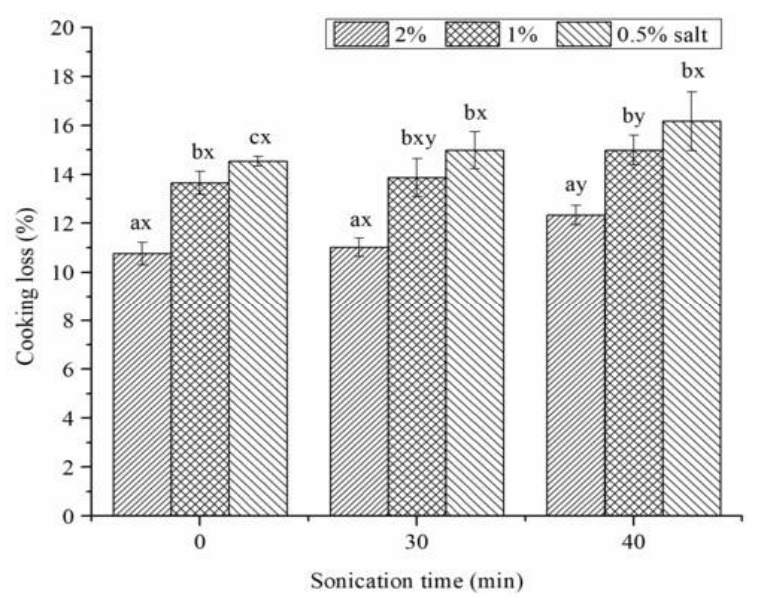

Figure 3: Cooking loss of fish meat gels. The letters a, $b$ and $c$ reflect significant differences $(p<0.05)$ among samples with different salt levels at the same sonication time. The letters $x$ and $y$ indicate significant differences $(p<0.05)$ between the two sonication times at the same salt level

\section{Structural features}

The microstructures of the four kinds of fish meat gels are presented in Figure 4. These are: sample containing $1 \%$ salt exposed to $30 \mathrm{~min}$ ultrasound, and sample containing $2 \%$ salt exposed to 0,30 and 40 min of ultrasound.

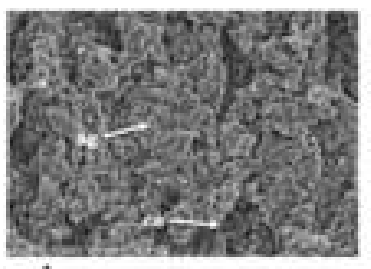

A

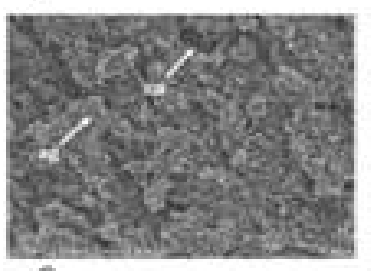

C

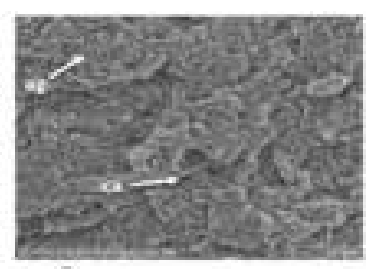

B

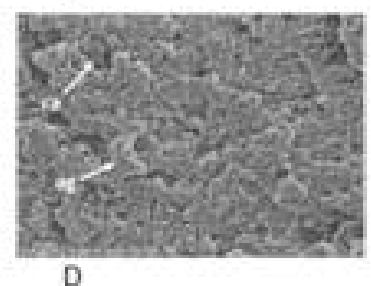

Figure 4: SEM images of ultrasound-treated fish meat gel with different salt level: (A) $1 \%$ salt exposed to $30-$ min ultrasound; (B) $2 \%$ salt unexposed to ultrasound; (C) $2 \%$ salt exposed to 30 -min ultrasound; (D) $2 \%$ salt exposed to 40-min ultrasound (x 3000; bar $=10.0$ $\mu \mathrm{m})(\mathrm{ag}=$ aggregate; $\mathrm{ca}=$ cavity)

\section{DISCUSSION}

In this study, low frequency ultrasound was used to develop reduced-salt gel of silver carp meat batter. The results showed that ultrasound treatment at decreasing salt levels increased the lightness $\left(L^{*}\right)$ value of fish meat gels. However, ultrasound treatment of samples at regular salt level produced the opposite effect. These results are supported by the findings of $\mathrm{Hu}$ et al [16], who reported that the whiteness values of squid muscle decreased on exposure to ultrasound treatment due to ultrasound-induced enhancement of browning reaction. On the other hand, reduction of salt level increased the $L^{*}$ value of samples, which is consistent with other studies $[15,17,18]$. This was attributed to the differences in levels of protein abstracted during chopping, and differences in salt content. It has been shown that increases in protein content decreased the $L^{*}$ value of beef meat batters [19]. This means that reduction of salt level might increase the $L^{*}$ value of samples. In the present study, cooking loss increased with reduction in salt content. Studies have shown that $L^{*}$ value is positively correlated with cooking loss [15]. This phenomenon might be due to heat-induced loss of water from the samples, resulting in accentuated light-scattering capacity of the meat batters.

The results also showed that with reduced salt levels, ultrasound treatment decreased the greenness $\left(-a^{*}\right)$ of fish meat gels, but increased the greenness in samples with regular salt levels. In addition, ultrasound treatment of samples with $1 \%$ salt content had no significant effect on yellowness $\left(b^{*}\right)$ of fish meat gels. Color is an important factor which determines the quality and acceptability of fish processing products such as surimi gels. Surimi gels with high lightness and low yellowness are generally in high demand [20].

In texture observations, the results showed that breaking force, distance to rupture and gel strength values of samples were affected by salt content and ultrasound treatments.

Ultrasound treatment in reduced salt samples decreased the breaking force and distance of rupture values of the fish meat gels, whereas, the ultrasound treatment gave the opposite effect on the breaking force values at regular-salt level and $1 \%$ salt of samples, and on the distance of rupture values of fish meat gels with normal salt content.

Some studies have also showed that salt had a positive effect on the mechanical properties of fish gel [4,21-24]. These studies showed that the breaking force, distance to rupture and gel strength of fish gel decreased at decreased salt concentration. Salt significantly influences the extraction and mechanical attributes of proteins 
[24]. Furthermore, other studies have revealed that the gel strength of chicken meat batters [25] and beef myofibrillar proteins [8] are positively influenced by ultrasound exposure. These effects are due to the fact that ultrasound exposure improves gel strength due to its effect on the degree of acidity of proteins, which in turn decreases sample particle size thereby resulting in increased solubility. However, prolonged ultrasound treatment causes denaturation of proteins and adversely influences the texture of products [12]. It has been reported that the gel strength of chicken breast meat batter with salt contents of $1,1.5$ and $2 \%$ tended to increase with 10 and $20 \mathrm{~min}$ ultrasound treatment, but decreased after 30 and $40 \mathrm{~min}$ sonication (40 $\mathrm{kHz}, 300 \mathrm{~W}$ ) [12].

In this study, reduction in salt levels increased the cooking loss value of fish meat gels. This finding is consistent with previous reports $[12,15,26]$. When salt level is increased, the hydration and water-binding characteristics of processed meats are increased [26]. Thus, decreases in salt level increase the cooking loss of samples. Studies have shown that salt contents of $1.5-2 \%$ result in solubilization of active myofibrillar proteins, thereby enhancing hydration and the binding capacity of the protein, resulting in better texture and less water loss during cooking [27]. As shown in the results of the present study, cooking losses of fish meat gels with 1 and $0.5 \%$ salt content were significantly higher than those of samples with regular salt level samples $(2 \%)$ at the same ultrasound treatment time. Ultrasound treatment significantly increased the cooking loss of fish meat gel samples with regular salt content, and samples with $1 \%$ salt content on exposure to 40 min of ultrasound. It has been reported that exposure of chicken meat gels to 20-min ultrasound reduced their water mobility and decreased their cooking loss at $\mathrm{NaCl}$ levels of 1 $-2 \%$, relative to cooking losses seen after their exposure to ultrasound for shorter or longer periods [12].

Results of SEM showed three dimensional networks in the sample of meat gels. The gel of regular-salt samples without sonication had visibly dense aggregates and low population of large cavities unevenly distributed. This sample presented a gel mesh of disorganized and dense aggregates, most likely as a result of disordered agglomeration prior to unfolding. When treated with ultrasound for $30 \mathrm{~min}$ and $40 \mathrm{~min}$, there was a reduction in the population of dense aggregates and an elevation in the population of uniformly distributed small cavities. Similar results were also reported by other researchers
$[9,25]$. Furthermore, SEM of reduced-salt sample (1\% salt content, 30 min ultrasound) showed a structure similar to that of non-sonicated, regular salt-containing sample.

\section{CONCLUSION}

The results obtained in this study demonstrate that it is feasible to obtain reduced-salt silver carp meat gels using low frequency ultrasound $(20 \mathrm{KHz}, 500 \mathrm{~W})$. The findings show that reduced-salt fish meat gels ( $1 \%$ salt) subjected to $30 \mathrm{~min}$ of sonication have better color (lighter) than control (0 $\mathrm{min}$ sonication), better texture (higher gel strength), and minimal changes in cooking loss, relative to samples containing regular salt level ( $2 \%$ salt). These products also have microstructures similar to regular-salt content sample without sonication. Thus, the findings suggest that low frequency ultrasound may be a useful technique for preparing reducedsalt fish meat gels using suitable ultrasonic conditions.

\section{DECLARATIONS}

\section{Acknowledgement}

This research was financially supported by China Agriculture Research System (no. CARS-45-26) and Project from Jiangsu Fishery Administration (no. Y2017-30). The authors express their thanks to Associate Professor Xiaolin Qiu, Packaging Engineering, School of Mechanical Engineering, Jiangnan University for providing the ultrasonicator employed in the experiments.

\section{Conflict of interest}

This investigation is not linked to any conflict of interest.

\section{Contribution of authors}

The authors declare that this work was done by those mentioned in this manuscript. All liabilities in respect of claims associated with the contents of this manuscript will be shouldered by the authors.

\section{Open Access}

This is an Open Access article that uses a funding model which does not charge readers or their institutions for access and distributed under the terms of the Creative Commons Attribution License (http://creativecommons.org/licenses/by/ 4.0) and the Budapest Open Access Initiative 
(http://www.budapestopenaccessinitiative.org/rea d), which permit unrestricted use, distribution, and reproduction in any medium, provided the original work is properly credited.

\section{REFERENCES}

1. Wang $Y$, Zhang M, Mujumdar AS, Mothibe KJ. Quality changes of dehydrated restructured fish product from silver Carp (Hypophthalmichthys molitrix) as affected by arying methods. Food Bioproc Tech 2012; 6: 16641680.

2. Xu Y, Xia W, Yang F, Nie X. Physical and chemical changes of silver carp sausages during fermentation with Pediococcus pentosaceus. Food Chem 2010; 122 : 633-637.

3. Liu H, Gao L, Ren Y, Zhao Q. Chemical interactions and protein conformation changes during silver carp (Hypophthalmichthys Molitrix) surimi gel formation. Int $\mathrm{J}$ Food Prop 2014; 17: 1702-1713.

4. Fu X, Hayat $K$, Li Z, Lin Q, Xu S, Wang S. Effect of microwave heating on the low-salt gel from silver carp (Hypophthalmichthys molitrix) surimi. Food Hydrocoll 2012; 27: 301-308.

5. Luo $Y$, Shen $H$, Pan $D, B u G$. Gel properties of surimi from silver carp (Hypophthalmichthys molitrix) as affected by heat treatment and soy protein isolate. Food Hydrocoll 2008; 22: 1513-1519.

6. Debusca A, Tahergorabi R, Beamer SK, Partington S, Jaczynski J. Interactions of dietary fibre and omega-3rich oil with protein in surimi gels developed with salt substitute. Food Chem 2013; 141: 201-208.

7. Pedro S, Nunes ML. Reducing salt in seafood products. In: Kilcast, David; Angus, Fiona, Editors. Reducing salt in foods, Practical strategies. 1st ed. Abington: Woodhead Publishing Limited; 2007; pp 256-282.

8. Amiri A, Sharifian $P$, Soltanizadeh $N$. Application of ultrasound treatment for improving the physicochemical, functional and rheological properties of myofibrillar proteins. Int J Biol Macromol 2018; 111: 139-147.

9. Saleem $R$, Ahmad $R$. Effect of low frequency ultrasonication on biochemical and structural properties of chicken actomyosin. Food Chem 2016; 205: 43-51.

10. Liu R, Liu Q, Xiong S, Fu Y, Chen L. Effects of high intensity unltrasound on structural and physicochemical properties of myosin from silver carp. Ultrason Sonochem 2017; 37: 150-157.

11. Higuera-Barraza OA, Torres-Arreola W, Ezquerra-Brauer JM, Cinco-Moroyoqui FJ, Rodriguez Figueroa JC, Marquez-Rios E. Effect of pulsed ultrasound on the physicochemical characteristics and emulsifying properties of squid (Dosidicus gigas) mantle proteins. Ultrason Sonochem 2017; 38: 829-834.

12. Li K, Kang ZL, Zou YF, Xu XL, Zhou GH. Effect of ultrasound treatment on functional properties of reduced-salt chicken breast meat batter. J Food Sci Technol 2015; 52: 2622-2633.
13. Carcel JA, Benedito J, Bon J, Mulet A. High intensity ultrasound effects on meat brining. Meat Sci 2007; 76: 611-619.

14. Sikes AL, Tobin AB, Tume RK. Use of high pressure to reduce cook loss and improve texture of low-salt beef sausage batters. Innov Food Sci Emerg Technol 2009; 10: 405-412.

15. Shao JH, Deng YM, Jia N, Li RR, Cao JX, Liu DY, Li JR. Low-field NMR determination of water distribution in meat batters with $\mathrm{NaCl}$ and polyphosphate addition. Food Chem 2016, 200, 308-314.

16. Hu Y, Yu H, Dong K, Yang S, Ye X, Chen S. Analysis of the tenderisation of jumbo squid (Dosidicus gigas) meat by ultrasonic treatment using response surface methodology. Food Chem 2014; 160: 219-225.

17. Cando D, Herranz B, Borderías AJ, Moreno HM. Effect of high pressure on reduced sodium chloride surimi gels. Food Hydrocoll 2015; 51: 176-187.

18. Fellendorf S, Kerry JP, Hamill RM, O'Sullivan MG. Impact on the physicochemical and sensory properties of salt reduced corned beef formulated with and without the use of salt replacers. Lebenson Wiss Technol 2018; 92: 584-592.

19. Youssef MK, Barbut S. Effects of protein level and fat/oil on emulsion stability, texture, microstructure and color of meat batters. Meat Sci 2009; 82: 228-233.

20. Hema K, Shakila RJ, Shanmugam SA, Jawahar. Functional properties of restructured surimi gel product prepared from low valued short nose white tripod fish (Triacanthus brevirosterus). J Food Process Technol 2016; 7:1-6.

21. Téllez-Luis SJ, Uresti RM, Ramírez JA, Vázquez M. Lowsalt restructured fish products using microbial transglutaminase as binding agent. J Sci Food Agric 2002; 82: 953-959.

22. Ramírez J, Uresti R, Téllez S, Vázquez M. Using Salt and Microbial Transglutaminase as Binding Agents in Restructured Fish Products Resembling Hams. J Food Sci 2002; 67: 1778-1784.

23. Uresti RM, Téllez-Luis SJ, Ramírez JA, Vázquez M. Use of dairy proteins and microbial transglutaminase to obtain low-salt fish products from filleting waste from silver carp (Hypophthalmichthys molitrix). Food Chem 2004; 86: 257-262..

24. Cardoso C, Mendes R, Vaz-Pires P, Nunes ML. Effect of salt and MTGase on the production of high quality gels from farmed sea bass. J Food Eng 2010; 101: 98-105.

25. Li K, Kang ZL, Zhao YY, Xu XL, Zhou GH. Use of highintensity ultrasound to improve functional properties of batter suspensions prepared from PSE-like chicken breast meat. Food Bioproc Tech 2014; 7: 3466-3477.

26. Herrero $A M$, Carmona $P$, López-López I, JiménezColmenero F. Raman spectroscopic evaluation of meat batter structural changes induced by thermal treatment and salt addition. J Agric Food Chem 2008; 56: 71197124.

27. Quadros DA, Bolini HMA. Effect of salt reduction and washing process of fish pulp on quality characteristics of 
Nasyiruddin et al

Serra Spanish mackerel (Scomberomorus brasiliensis)

52: $7449-7456$

fish burgers for school meals. J Food Sci Technol 2015; 